\title{
Silencing CoREST inhibits the viability and migration of fibroblast-like synoviocytes in TNF- $\alpha$-induced rheumatoid arthritis
}

\author{
ZILIANG YU $^{1 *}$, FEIHU CHEN ${ }^{2 *}$, HAO LIU ${ }^{3}$, JIANBO FAN $^{1}$, XIAOMIN DING ${ }^{1}$, XINHUI ZHU $^{1}$, \\ SHENGYU CUI ${ }^{1}$, HONG YI ${ }^{1}$, XIAOGANG ZHOU ${ }^{1}$, YALONG HU ${ }^{1}$ and WEI LIU ${ }^{1}$ \\ ${ }^{1}$ Department of Orthopaedics, The Second Affiliated Hospital of Nantong University, Nantong, Jiangsu 226001; \\ ${ }^{2}$ Department of Orthopaedics, Xuyi People's Hospital, Xuyi, Jiangsu 211700; ${ }^{3}$ School of Clinical Medicine, \\ Nanjing Medical University, Nanjing, Jiangsu 211166, P.R. China
}

Received November 26, 2019; Accepted October 8, 2021

DOI: $10.3892 /$ etm.2021.11071

\begin{abstract}
Fibroblast-like synoviocytes (FLSs) have functions in the pathogenesis of rheumatoid arthritis (RA) through the onset of synovitis, the growth of pannus and the destruction of cartilage and bone. The significant increase in the proliferation, migration and invasion of FLSs induces the onset and advancement of RA. To date, the exact function of corepressor element-1 silencing transcription factor (CoREST) in RA remains unclear, but its expression has been determined in RA synovial tissues. In this study, the effects of CoREST were investigated in a TNF- $\alpha$-induced FLS activation model. Following the silencing of CoREST expression with small interfering (si)RNA, the viability and migration of FLSs were evaluated. Furthermore, the possible molecular mechanisms were explored by detecting the expression of key factors, including matrix metalloproteinases (MMPs), lysine-specific histone demethylase 1 (LSD1) and associated cytokines, via reverse transcription-quantitative PCR and western blotting. CoREST expression increased not only in the RA synovial tissues, but also in the TNF- $\alpha$-induced FLS activation model. Following the silencing of CoREST in the FLSs treated with TNF- $\alpha$, cell viability was inhibited, and the migratory capacity of FLSs was suppressed, which was accompanied by the reduced expression of MMP-3 and MMP-9. The expression of LSD1 was also downregulated. There was a notable decrease in the synthesis of interferon- $\gamma$ and interleukin (IL)-17, while
\end{abstract}

Correspondence to: Dr Wei Liu, Department of Orthopaedics, The Second Affiliated Hospital of Nantong University, 6 North Hai-Er-Xiang Road, Nantong, Jiangsu 226001, P.R. China

E-mail: liuweidr@yeah.net

"Contributed equally

Key words: fibroblast-like synoviocytes, corepressor element-1 silencing transcription factor, rheumatoid arthritis, lysine-specific histone demethylase 1
IL-10 expression was increased. The knockdown of CoREST inhibited the viability and migration of FLSs stimulated with TNF- $\alpha$. Thus, the suppression of CoREST may have crucial roles in the occurrence and development of RA.

\section{Introduction}

Rheumatoid arthritis (RA) is a complicated systemic disease that manifests as chronic synovial inflammation and leads to the gradual damage of the articular cartilage, loss of joint functions and comorbidity with the extraarticular organs (1). A study in Italy reported that the incidence rate of RA was $0.038 \%$ in women and $0.013 \%$ in men $(2,3)$. A study in South Korea reported that the incidence of RA was higher for individuals $>60$ years old (4). The pathogenesis of RA is not yet fully understood.

RA is associated with a number of factors, such as dysregulated gene expression, and environmental and stochastic factors. Several studies have demonstrated that environmental factors, including smoking (5), exposure to inhaled particulate air pollution (6) and multiple dietary (7), are risk factors for rheumatoid-factor positive RA. Early diagnosis of RA is important for effective treatment, and a longer course of disease can lead to worse outcomes (8). Thus, it is necessary to develop efficient diagnostic and therapeutic methods. Fibroblast-like synoviocytes (FLSs) are one of the most common and dominant type of effector cells found in synovial joints that bear several features of malignant cells, such as abundant cytoplasm, large pale nuclei with several prominent nucleoli and a dense, rough endoplasmic reticulum (9-12). Results of our previous studies demonstrated that dual-specificity tyrosine-regulated kinase 1A (Dyrk1A) can promote the proliferation, migration and invasion of FLSs through the suppression of protein sprouty homolog 2 and the activation of the ERK/MAPK signaling pathway in patients with RA (13). In addition to the aggressive proliferative and migratory patterns, FLSs also secrete matrix metalloproteinases (MMPs), for example MMP-9 and MMP-3 (14), which destroy collagen bundles within the cartilages, thereby assisting the invasion of cartilage and bone (15). 
Researchers have been focusing on suppressing the abnormal activation of FLSs as a novel method to treat RA (16). The repressor element-1 silencing transcription factor (REST) is a transcription factor consisting of a DNA-binding domain and two repressor domains $(17,18)$. REST corepressor (CoREST) is a functional corepressor that assumes several roles in regulating the expression of neuron-specific genes. CoREST contains two SANT (SW13/ADA2/NCoR/TFIIIB B) domains, a structural feature of the nuclear receptor, and silencing mediator for retinoid and thyroid human receptors (SMRT)-extended corepressors that mediate inducible repression by steroid hormone receptors (19). The role of lysine-specific histone demethylase 1 (LSD1) in RA has been investigated. In CD4 ${ }^{+} \mathrm{T}$ cells obtained from active RA synovial fluids, LSD1 knockdown can significantly promote cell proliferation, while also significantly increasing the synthesis of interferon- $\gamma($ IFN- $\gamma)$, interleukin (IL)-17 and IL-10 (20). An in vivo study indicated that LSD1 knockdown significantly alleviated disease severity (20). The repressed activity of LSD1 has been shown to depend on its interaction with CoREST (21-23). It has been reported that LSD1 can act as a negative regulator of the Notch signaling pathway through its interaction with the deacetylase sirtuin 1 (SIRT1) in cell cultures (24). Previous studies have shown that interfering with the CoREST/LSD1 complex can slow down the development of the cerebral cortex by delaying cell differentiation $(25,26)$. However, the roles of CoREST in the pathogenesis of RA are still unknown.

In the present study, the expression levels of CoREST in the synovial tissues of patients with RA were investigated. Furthermore, the effects of CoREST on the proliferative, migratory and invasive patterns of RA-FLSs were evaluated, and the fundamental processes involved in the pathological process of RA was explored.

\section{Materials and methods}

Patient selection. A total of 14 patients with RA were involved in this study, including 7 female and 7 male patients. Patients hospitalized in The Second Affiliated Hospital of Nantong University (Nantong, China) from October 2018 to April 2019 were selected. They were selected according to the 2010 American College of Rheumatology/European League Against Rheumatism Classification Criteria for Rheumatoid Arthritis and other immune system related diseases were excluded (27). The inclusion criteria were as follows: i) DAS-28 score was $>2.6$; ii) no previous diagnosis of other immune-related diseases; and iii) had not taken any medication for RA within the year before the operation. The synovial tissues were obtained from the patients while they underwent total knee replacement or arthroscopic surgeries. Normal synovial tissues were obtained from another 14 healthy volunteers through arthroscopic procedures. The average ages of patients were $45 \pm 6$ and $47 \pm 5$ years old for patients with RA and healthy controls, respectively. The procedures and processes of the present study were reviewed and approved by the institutional medical ethics committee of Affiliated Hospital 2 of Nantong University, Nantong, China (approval no. 2019KY126). Patients provided written informed consent to participate before they received any treatment.
Cell culture and TNF- $\alpha$ treatment. The synovial tissues were sliced into 2-4 $\mathrm{mm}$ sections and left to degrade for $4 \mathrm{~h}$ at $37^{\circ} \mathrm{C}$ with collagenase I (Gibco; Thermo Fisher Scientific, Inc.) in Hanks' balanced salt solution (Beyotime Institute of Biotechnology). Following centrifugation at $111.8 \times \mathrm{g}$ and room temperature for $5 \mathrm{~min}$, cells obtained from the synovial tissues were cultured in Dulbecco's modified Eagle's medium (DMEM)/F12 medium (Gibco; Thermo Fisher Scientific, Inc.) with $100 \mathrm{U} / \mathrm{ml}$ penicillin, $100 \mu \mathrm{g} / \mathrm{ml}$ streptomycin (HyClone; Cytiva) and 10\% fetal bovine serum (FBS; Gibco; Thermo Fisher Scientific, Inc.). Cells were incubated in a humidified incubator with $5 \% \mathrm{CO}_{2}$ at $37^{\circ} \mathrm{C}$. Cells at passages 3-8 were utilized for the present study. A total of $10 \mathrm{ng} / \mathrm{ml} \mathrm{TNF}-\alpha$ (PeproTech, Inc.) was used to stimulate FLSs for $24 \mathrm{~h}$ in a humidified incubator with $5 \% \mathrm{CO}_{2}$ at $37^{\circ} \mathrm{C}$. Following treatment with TNF- $\alpha$, FLSs were collected for subsequent experiments.

Immunohistochemistry (IHC) analysis. Harvested synovial tissues were fixed in $4 \%$ paraformaldehyde at $4^{\circ} \mathrm{C}$ for $24 \mathrm{~h}$ and subsequently embedded in paraffin. The embedded tissue was cut into $5-\mu \mathrm{m}$ slices. A total of $100 \mu \mathrm{l}$ blocking buffer [10\% FBS (cat. no. F8318; Sigma-Aldrich; Merck KGaA) in 1X PBS (Sangon Biotech)] was added to the sections, and these were incubated in a humidified chamber at room temperature for $1 \mathrm{~h}$. The blocking buffer was subsequently drained from the slices. The IHC analysis was carried out using a primary antibody against CoREST (1:100; cat. no. 07-455; Sigma-Aldrich; Merck $\mathrm{KGaA}$ ) at $4^{\circ} \mathrm{C}$ overnight, and the slices were subsequently washed with $1 \mathrm{X}$ PBS (Sangon Biotech) twice for $5 \mathrm{~min}$ each. The slices incubated in a humidified chamber at room temperature for $1 \mathrm{~h}$ with a horseradish peroxidase (HRP)-conjugated secondary antibody (1:4,000; cat. no. 12-348; Sigma-Aldrich; Merck KGaA). The slices were subjected to immunoperoxidase staining performed using an HRP/diaminobenzidine IHC detection kit (cat. no. ab64264; Abcam). The slices were photographed using a Bx53 LED fluorescent microscope (Olympus Corporation).

Knockdown of CoREST with small interfering (si)RNA transfection. The CoREST expression in FLSs was knocked down with human CoREST siRNA (siCoREST) and the synthetic siRNA was applied as a negative control (siNC; Guangzhou RiboBio Co., Ltd.). The target sequence of the CoREST siRNA was 5'-AAGAUUGUCCCGUUCUUG ACU-3', and the sequence of the control siRNA was 5'-UUG AUGUGUUUAGUCGCUA-3'. The control siRNA sequence was purchased from Guangzhou RiboBio Co., Ltd. The treatment concentration of all siRNAs was $40 \mathrm{nmol}$. Transient transfection of siRNA was achieved using riboFECTTM CP Reagent (Guangzhou RiboBio Co., Ltd.), according to the manufacturer's recommendations. Following the transfection of siRNA, cells were incubated and cultured in serum-free medium for $6 \mathrm{~h}$, and then transferred to total medium that contained $10 \%$ FBS for a further $48 \mathrm{~h}$. After verifying the knockdown of CoREST, the cells were applied for further experiments.

Cell Counting Kit-8 (CCK-8) assay. In order to examine the proliferation of FLSs, a CCK-8 assay was performed. Cells 
were seeded into 96-well plates at a density of $1 \times 10^{3}$ cells/well and tested for viability at $24 \mathrm{~h}$. To determine cell proliferation, CCK-8 reagent was added into each well (10 $\mu \mathrm{l} /$ well). The cells were incubated at $37^{\circ} \mathrm{C}$ for $1.5 \mathrm{~h}$ with $5 \% \mathrm{CO}_{2}$, and the absorbance was recorded at $450 \mathrm{~nm}$ with an ELISA plate reader for each well. The histogram of cell viability was constructed using GraphPad Prism 8.0 software (GraphPad Software, Inc.).

Wound healing assay. FLSs were seeded into 6-well plates at a density of $2 \times 10^{5}$ cells/well. Once the cell confluence reached $90 \%$, sterile pipette tips were used to create wounds. Detached cells were washed with phosphate buffer saline and the medium was replaced with DMEM/F12 containing 2\% FBS. Images were captured at 0 and $24 \mathrm{~h}$ using a Bx53 LED fluorescent microscope (Olympus Corporation) and subsequently examined using ImageJ software (version 1.51j8; National Institutes of Health) to count the cells beyond the reference line.

$R N A$ isolation and reverse transcription-quantitative PCR $(R T-q P C R)$. TRIzol ${ }^{\circledR}$ reagent (Invitrogen; Thermo Fisher Scientific, Inc.) was used mainly for total mRNA extraction from fibroblast-like synoviocytes, following which, the products were reverse transcribed into cDNA using a RevertAid First Strand cDNA Synthesis Kit according to the manufacturer's protocol (Thermo Fisher Scientific, Inc.). qPCR was performed using PowerUp ${ }^{\mathrm{TM}} \mathrm{SYBR}^{\mathrm{TM}}$ Green Master Mix (Thermo Fisher Scientific, Inc.) on a StepOnePlus ${ }^{\mathrm{TM}}$ Real-Time PCR System (Applied Biosystems; Thermo Fisher Scientific, Inc.). The thermocycling conditions of qPCR were as follows: Initial denaturation at $95^{\circ} \mathrm{C}$ for $5 \mathrm{~min}$, followed by 35 cycles of denaturation at $95^{\circ} \mathrm{C}$ for $30 \mathrm{sec}$, annealing at $60^{\circ} \mathrm{C}$ for $30 \mathrm{sec}$ and extension at $72^{\circ} \mathrm{C}$ for $30 \mathrm{sec}$. The relative expression of target mRNA was normalized to $\beta$-actin as an endogenous control and quantified using the $2^{-\Delta \Delta \mathrm{Cq}}$ method (28). The primers applied in this study were as follows: MMP-3 forward (F), 5'-GACAAAGGATACAACAGGGACCAAT-3' and reverse (R), 5'-TGAGTGAGTGATAGAGTGGGTACAT-3'; MMP-9 F, 5'-TGCCCGGACCAAGGATACAG-3' and R, 5'-CAGGGCGAGGACCATAGAG-3'; and $\beta$-actin F, 5'-GTC GGTGTGAACGGATTTG-3' and R, 5'-TCCCATTCTCAG CCTTGAC-3'.

Western blotting. Total protein was extracted from cells obtained from the synovial tissues of patients using 1X PBST [1X PBS (Sangon Biotech) and 1\% Triton X-100, (Sigma-Aldrich; Merck KGaA)]. Total protein was quantified using a BCA assay kit (Beyotime Institute of Biotechnology). A total of $10 \mu \mathrm{g}$ protein per lane was loaded on a $10 \% \mathrm{gel}$, and proteins were separated by SDS-PAGE. Proteins were transferred onto PVDF membranes, and these were incubated with $10 \%$ milk at room temperature for $1 \mathrm{~h}$. Subsequently, the PVDF membranes were incubated with the following antibodies: Anti-CoREST (1:1,000; cat. no. 07-455; Sigma-Aldrich), rabbit anti-human LSD1 (1:1,000; cat. no. A8711; Abclonal), anti- $\beta$-actin (1:4,000; cat. no. ab8227; Abcam), anti-proliferating cell nuclear antigen (PCNA; 1:1,000; cat. no. ab18197; Abcam), anti-MMP-3 (1:1,000; cat. no. AF7482; Beyotime Institute of Biotechnology) and anti-MMP-9 (1:1,000; cat. no. AF5234; Beyotime Institute of Biotechnology) at $4^{\circ} \mathrm{C}$ overnight. Following primary incubation, membranes were washed using PBS with $0.05 \%$ Tween-20 five times, followed by incubation for $1 \mathrm{~h}$ at room temperature with a HRP-conjugated secondary antibody (1:4,000; cat. no. 12-348; Sigma-Aldrich; Merck KGaA). The membrane was developed using an electrochemiluminescence kit (Pierce; Thermo Fisher Scientific, Inc.). $\beta$-actin expression was used for normalization. All the experiments were performed in triplicate. The results of western blots were analyzed using the ImageJ software (version 1.38; National Institutes of Health).

Data analysis. Results are presented as the mean \pm standard deviation (SD). Data were analyzed using SPSS software version 19.0 (IBM Corp.). An unpaired Student's t-test was performed to compare statistically significant differences between two groups, while one-way ANOVA followed by Dunnett's post hoc test was applied for $>2$ groups. $\mathrm{P}<0.05$ was considered to indicate a statistically significant difference. All experiments in our study were performed independently at least three times.

\section{Results}

Upregulation of CoREST in RA synovial tissues. Western blotting was performed to detect the expression of CoREST in the synovial tissues of patients with RA and healthy controls (Fig. 1A). There was a significant increase in the expression of CoREST in the RA group compared with in the control group (Fig. 1B). The IHC analysis demonstrated that CoREST expression was higher in the RA group compared with the control group (Fig. 1C). FLSs, which have important roles in the onset and disease progression of RA (29), were found in both RA and healthy synovial tissues. The shredded tissue appeared as a black mass under the microscope (data not shown). After 3-5 days of adhesion, the edge of the tissue appears as a gray image (Fig. 1D), indicating that cells had moved from the border of the adherent tissue. By passage three, the RA-FLSs showed spindle-shaped and whirlpool-like morphological characteristics while growing under a light microscope (Fig. 1E).

CoREST knockdown alleviates TNF- $\alpha$-induced CoREST expression and the proliferation of FLSs. To further evaluate the function of CoREST in RA-FLSs, a TNF- $\alpha$-induced FLS activation model was included as previously described (30-32). Briefly, following treatment with TNF- $\alpha$ (10 ng/ml), CoREST expression was significantly upregulated in FLSs in a time-dependent manner (Fig. 2A). To elucidate the potential influence of CoREST on the proliferation of FLSs, CoREST expression was knocked down with siCoREST (Fig. S1). Following transfection with siCoREST, the expression of CoREST in TNF- $\alpha$-induced FLSs was significantly inhibited as compared with that of the control group (Fig. 2B). PCNA is a marker of cell proliferation (26). After the silencing of CoREST expression by siCoREST, the expression of PCNA was also significantly reduced as compared with that in the control group (Fig. 2B). The effects of CoREST on the cell proliferation of FLSs stimulated with TNF- $\alpha$ were determined via a CCK- 8 assay. The cell viability of TNF- $\alpha$-stimulated FLSs was significantly suppressed after the silencing of CoREST compared with the control group (Fig. 2C). 


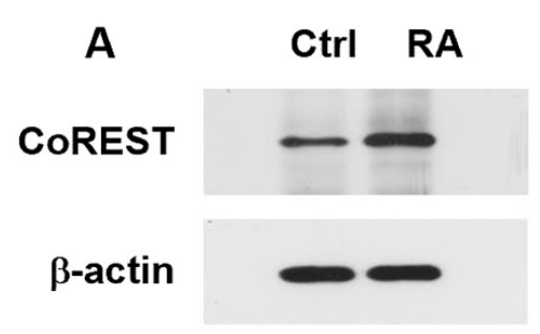

C

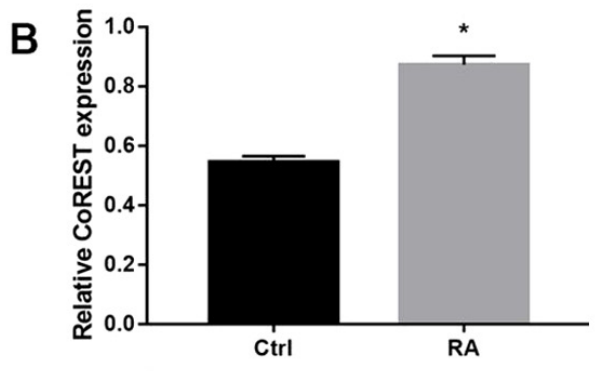

RA

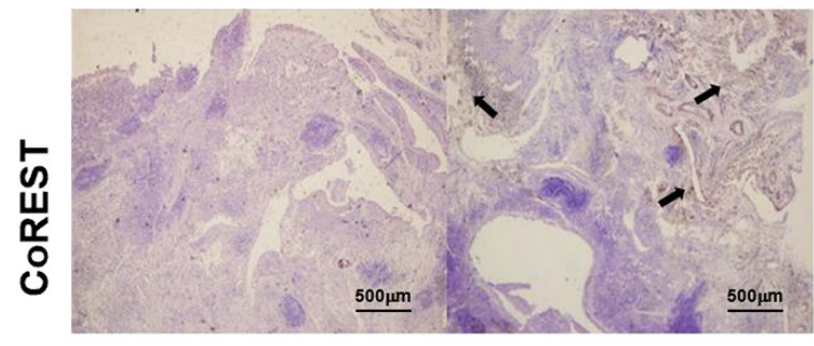

D

E

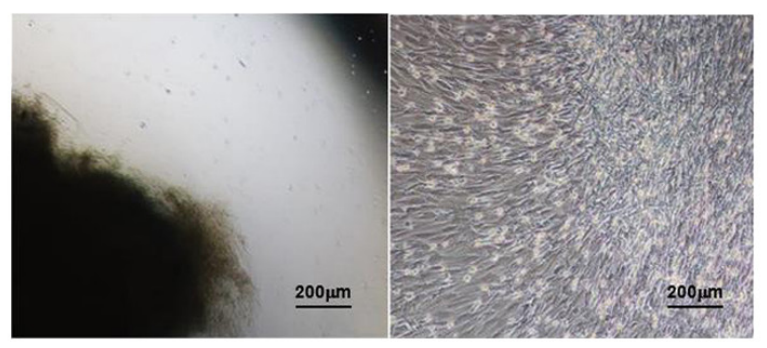

Figure 1. CoREST expression is upregulated in RA synovial tissues. (A and B) The expression of CoREST in synovial tissues from patients with RA and healthy controls (unpaired t-test). (C) Immunohistochemistry analysis of CoREST expression in synovial tissues from patients with RA and healthy controls (arrows indicate that CoREST is highly expressed in the tissues of patients with RA). (D) RA-FLSs moved out of the synovial tissues. (E) RA-FLSs at passage three showed spindle-shaped and whirlpool-like morphological characteristics. Data are presented as the mean $\pm \mathrm{SD}$ of three independent experiments. "P $<0.05$ vs. control. CoREST, corepressor element-1 silencing transcription factor; RA, rheumatoid arthritis; FLSs, fibroblast-like synoviocytes; RA-FLSs, fibroblast-like synoviocytes from patients with RA.

A
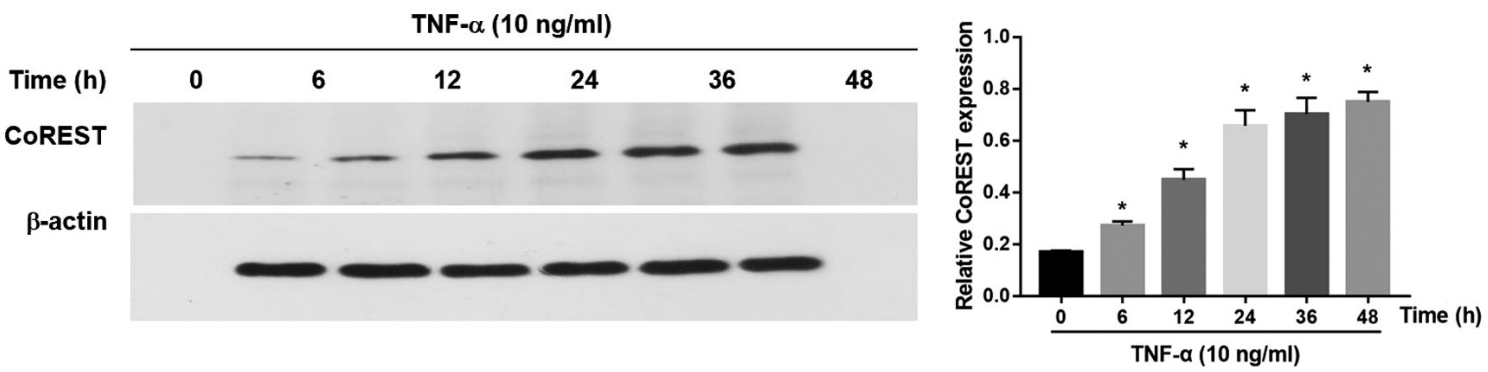

B
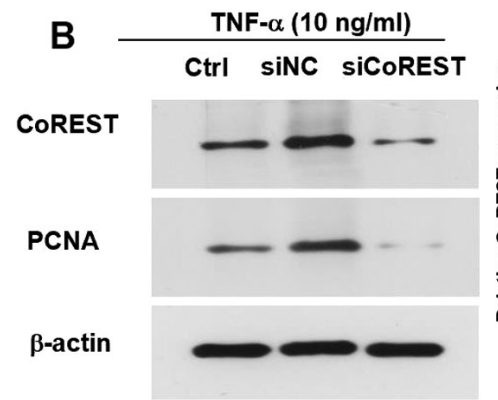
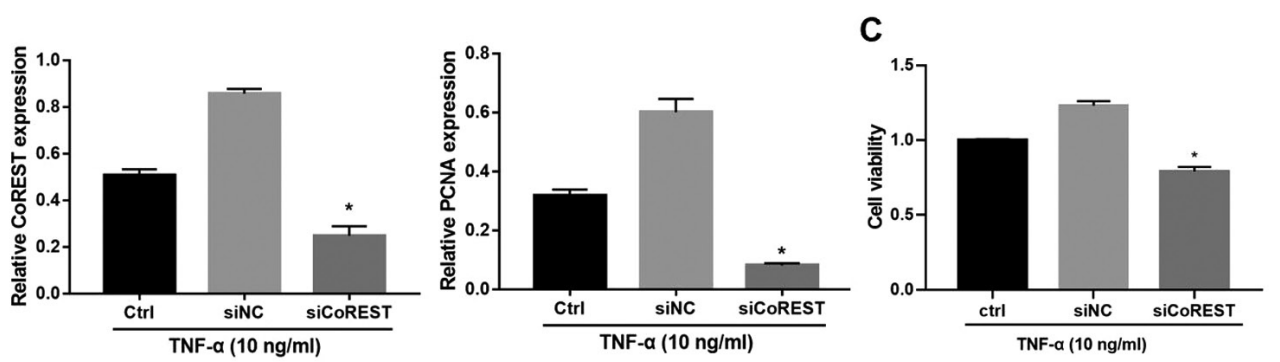

Figure 2. CoREST expression in FLSs stimulated with TNF- $\alpha$. (A) CoREST expression in FLSs stimulated with TNF- $\alpha$ (10 ng/ml) for $0,6,12,24,36$ and $48 \mathrm{~h}$, as determined via western blotting. (B) The expression levels of CoREST and PCNA in TNF- $\alpha$-stimulated FLSs were determined by western blotting following the knockdown of CoREST expression with siCoREST. The processed siRNA was applied as the negative control (siNC). (C) Transfection with siCoREST suppressed the proliferation of TNF- $\alpha$-stimulated FLSs. Data are presented as the mean \pm SD. ${ }^{*} \mathrm{P}<0.05$ vs. the siNC group. CoREST, corepressor element-1 silencing transcription factor; FLSs, fibroblast-like synoviocytes; PCNA, proliferating cell nuclear antigen; si, small interfering RNA; NC, negative control. 

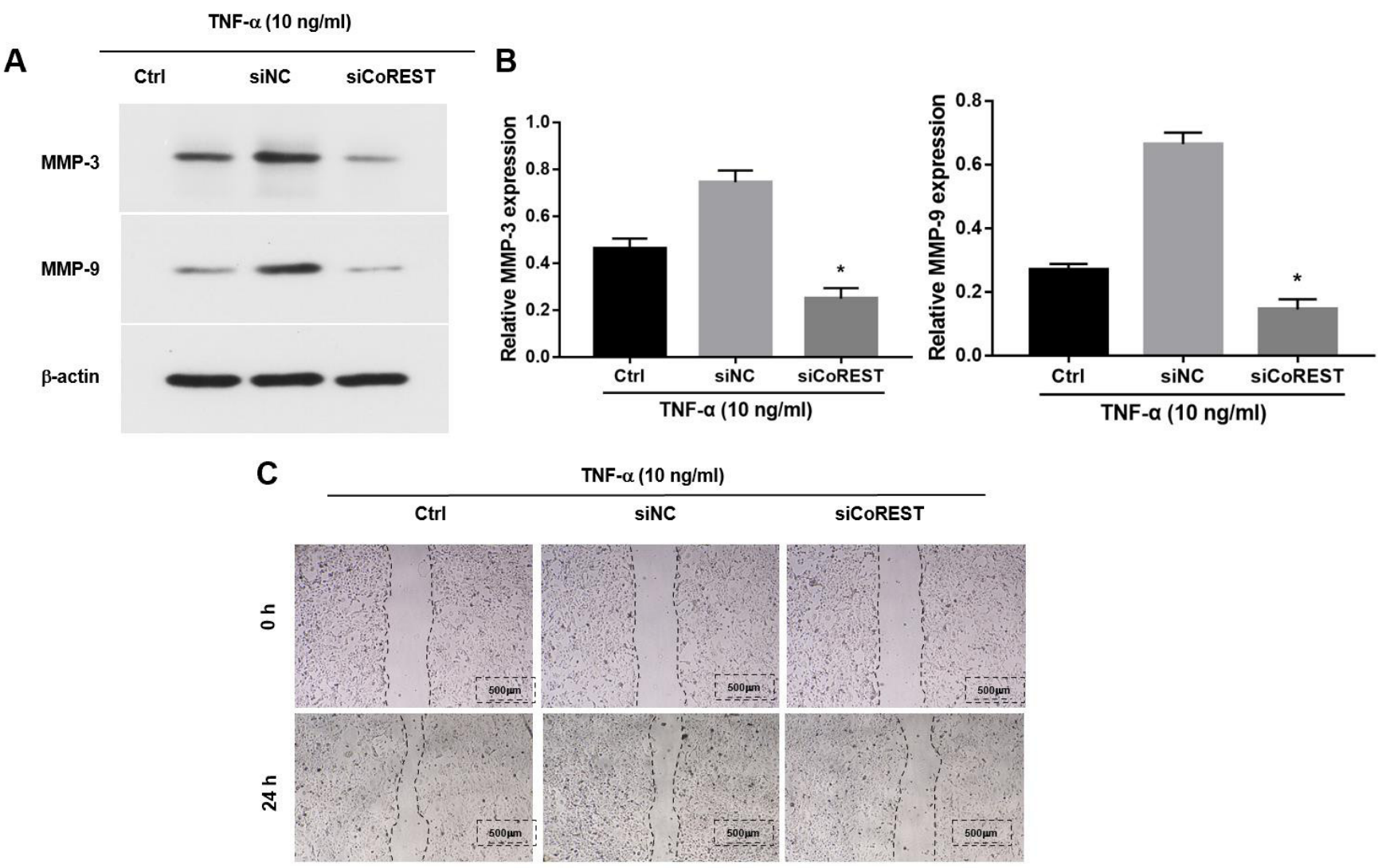

Figure 3. Silencing of CoREST inhibits the migratory and invasive abilities of TNF- $\alpha$-stimulated FLSs. The (A) protein and (B) mRNA expression levels of MMP-3 and MMP-9 were determined via western blotting and reverse transcription-quantitative PCR, respectively. The relative expression levels were normalized to that of the internal control. (C) The migratory ability of FLSs was examined by a wound healing assay. Scale bar, $500 \mu \mathrm{m}$. Data are presented as the mean $\pm \mathrm{SD}$. ${ }^{*} \mathrm{P}<0.05$ vs. the siNC group. CoREST, corepressor element-1 silencing transcription factor; FLSs, fibroblast-like synoviocytes; si, small interfering RNA; NC, negative control.

Knockdown of CoREST inhibits the migratory and invasive abilities of TNF- $\alpha$-stimulated FLSs. MMPs are a group of zinc-dependent homologous proteases (33). A distinct and typical clinical indicator observed in patients with RA is elevated levels of MMPs including MMP-9 and MMP-3, which are associated with the increased migration and invasion of FLSs (14). Previous studies have shown that stimulation with TNF- $\alpha$ elevated the expression levels of MMP-9 and MMP-3 (34). However, following transfection with siCoREST, the TNF- $\alpha$-induced upregulation of MMPs was significantly inhibited compared with the control group (Fig. 3A and B). The effects of CoREST on the migration of FLSs were further explored by performing a wound healing assay. Transfection with siCoREST notably inhibited the migratory ability of FLSs compared with the control group (Fig. 3C).

Knockdown of CoREST downregulates the expression of LSD1. The expression of LSD1 was upregulated in patients with RA (Fig. 4A and B). The effect of CoREST on the expression of LSD1 was further explored. Following treatment with TNF- $\alpha$, the expression of LSD1 in FLSs was significantly increased at 12, 24 and $36 \mathrm{~h}$, and then began to decrease at $48 \mathrm{~h}$ (Fig. 4C and D). Following transfection with siCoREST, the expression of LSD1 was significantly downregulated compared with the control group (Fig. 4E and F). Furthermore, silencing of CoREST significantly suppressed the production of IFN- $\gamma$ and IL-17 and promoted the expression of IL-10 ( $\mathrm{P}<0.05$; Fig. 5A and $\mathrm{B})$.

\section{Discussion}

RA is a complicated systemic disease (1), and a considerable number of studies have demonstrated that increased proliferation, migration and invasion of FLSs leads to the damage of arthrodial cartilage that advances the pathogenesis of RA $(12,35,36)$. The present study revealed that CoREST and its corepressor protein LSD1 were highly expressed in RA synovial tissues. A previous in vivo study indicated that LSD1 knockdown significantly alleviated disease severity (20). The results of the current study gave support for the hypothesis that there is a molecular relationship between the LSD1/CoRST complex in RA-FLSs. However, to the best of our knowledge, there have been few functional investigations into the LSD1/CoREST complex outside of the neural system.

LSD1 is a well-characterized histone demethylase that regulates gene transcription and chromatin configuration through epigenetic modifications (37). The tower motif, which is crucial for the catalytic activity of LSD1, acts as an adaptor to recruit other proteins, such as CoREST (37). LSD1 demethylates $\mathrm{H} 3 \mathrm{~K} 4 \mathrm{me} 1 / \mathrm{me} 2$ in a CoREST complex-dependent manner and functions as a transcription repressor (38). In the present study, the elevated expression of CoREST was observed in 

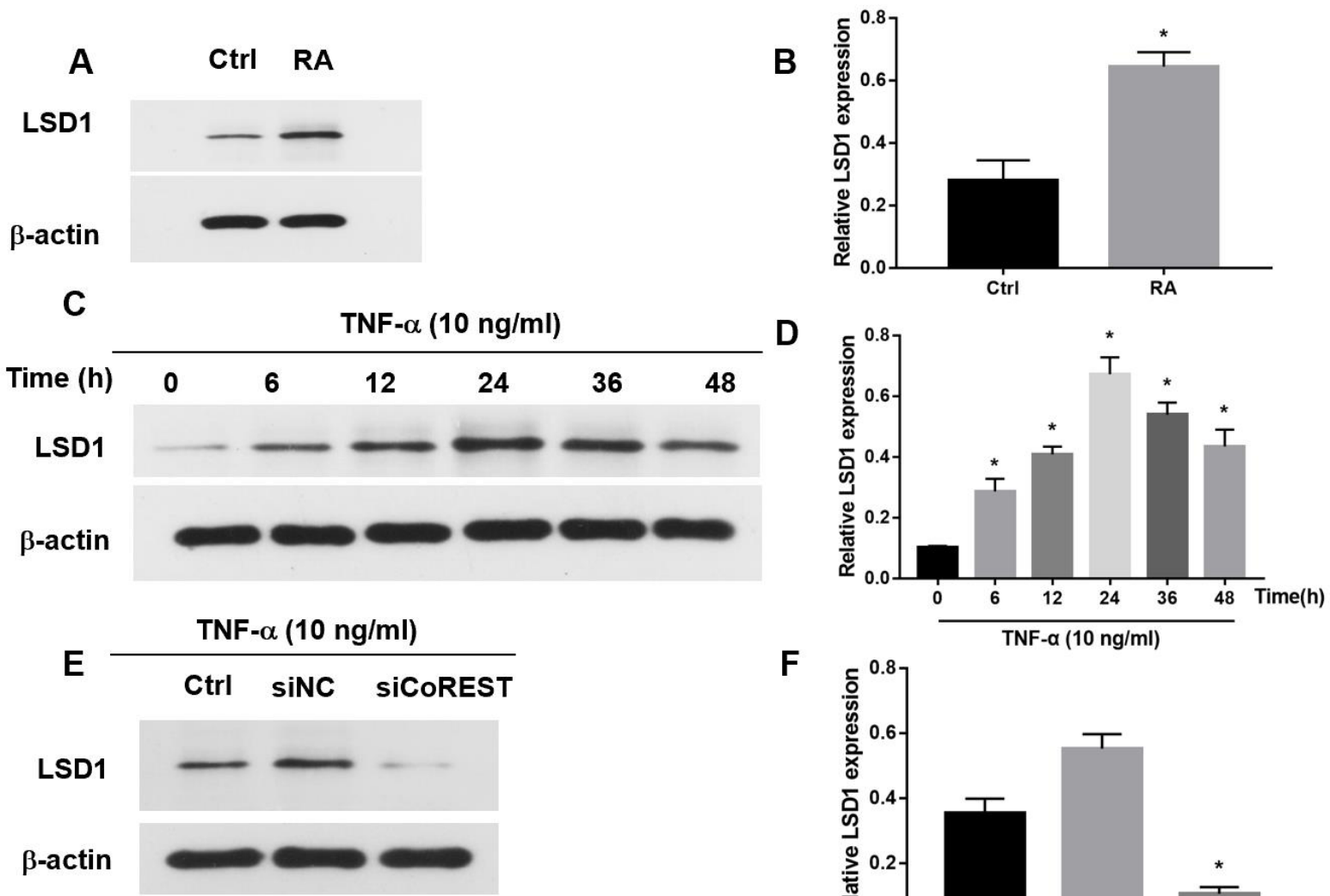

$\mathbf{F}$

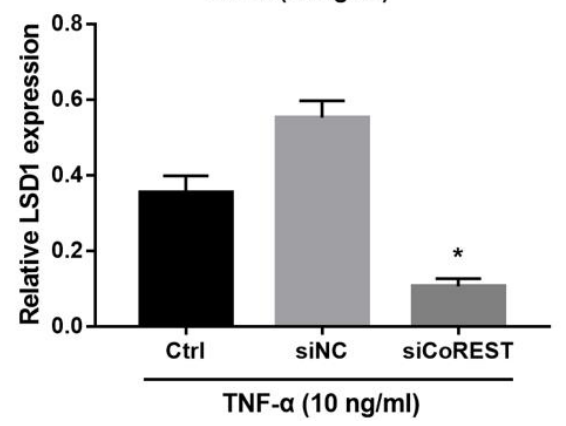

Figure 4. Knockdown of CoREST expression leads to the downregulation of LSD1 expression in TNF- $\alpha$-stimulated FLSs. (A and B) LSD1 expression was increased in synovial tissues from patients with RA compared with those from the healthy controls (unpaired t-test). (C and D) The expression of LSD1 was gradually increased in FLSs following treatment with TNF- $\alpha$ for 6, 12, 24, 36 and $48 \mathrm{~h}$. (E and F) The expression of LSD1 was decreased after the silencing of CoREST in FLSs. Data are presented as the mean \pm SD. " $\mathrm{P}<0.05$ vs. the siNC group. CoREST, corepressor element-1 silencing transcription factor; FLSs, fibroblast-like synoviocytes; LSD1, lysine-specific histone demethylase 1; RA, rheumatoid arthritis; si, small interfering RNA; NC, negative control.
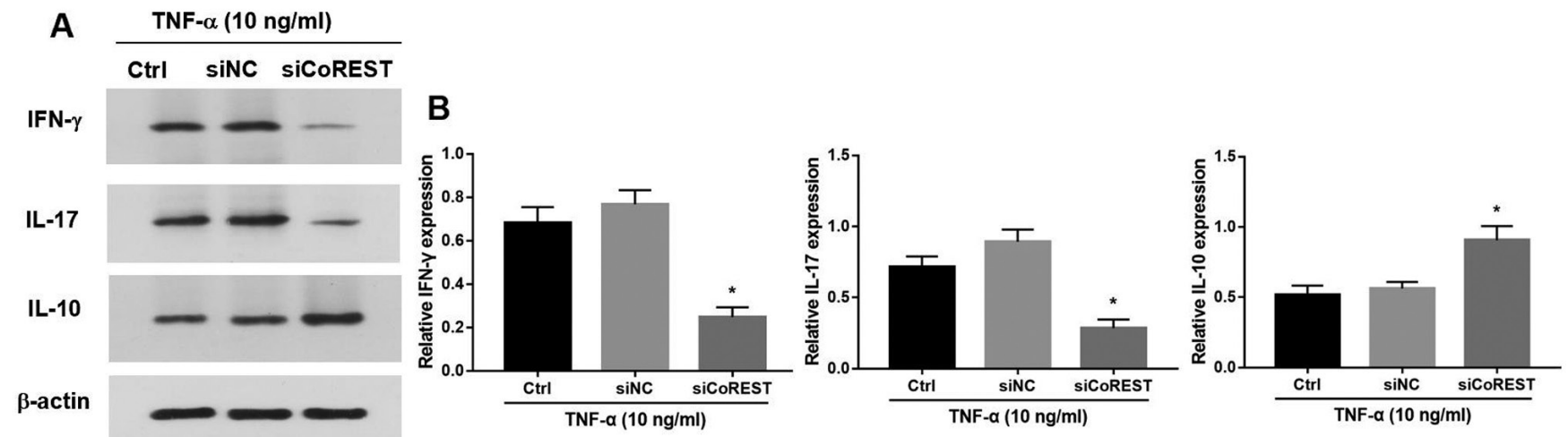

Figure 5. Knockdown of CoREST inhibits the expression of IFN- $\gamma$ and IL-17, and promotes the expression of IL-10 in the supernatant of TNF- $\alpha$-stimulated fibroblast-like synoviocytes. (A) Western blotting analysis demonstrated the effects of CoREST on IFN- $\gamma$, IL-17 and IL-10. (B) Protein expression of the targeted protein was normalized to that of $\beta$-actin. Data are presented as the mean \pm SD. " $\mathrm{P}<0.05$ vs. the siNC group. CoREST, corepressor element- 1 silencing transcription factor; si, small interfering RNA; NC, negative control; IFN- $\gamma$, interferon- $\gamma$; IL, interleukin.

RA-FLSs, which confirmed that the LSD1/CoREST complex may exert effects on RA-FLSs.

FLSs are transferred to an activated state by stimulation with proinflammatory cytokines, such as TNF- $\alpha$, which induces increased proliferative, migratory and invasive abilities (39). The aforementioned effects resemble the features of active RA progression. The current study demonstrated that proliferation, migration of FLSs treated with TNF- $\alpha$ could be reduced by the inhibition of CoREST. With TNF- $\alpha$ stimulation, the expression of CoREST in FLSs was increased as compared with that in the controls. Meanwhile, the expression of LSD1 was also upregulated. 
In the TNF- $\alpha$-stimulated RA-FLSs, CoREST expression was upregulated in a time-dependent manner. LDS1 expression was mildly elevated within the first $12 \mathrm{~h}$, reaching a peak at $24 \mathrm{~h}$ and gradually deceasing at $36 \mathrm{~h}$. This variation may be the result of effects in the early phase, in which TNF- $\alpha$ may function in the activation process and also trigger the mechanisms responsible for self-protection within FLSs. The expression of CoREST was relatively low, with limited effects, thus, the expression of LSD1 was only slightly elevated. After $36 \mathrm{~h}$, with the accumulation of CoREST, the function and expression of LSD1 was mostly eliminated. This hypothesis was further confirmed by the knockdown of CoREST with siRNA, which caused the expression of LSD1 to decrease, thus suggesting that CoREST had a positive regulatory effect on LSD1 in RA-FLSs. These results indicated that the LSD1/CoREST complex may worked together towards the TNF- $\alpha$-stimulated RA-FLSs. The molecular mechanism of the role of the LSD1/CoREST complex in RA is still unclear. The Notch signaling pathway, a crucial pathway in RA pathogenesis, has been demonstrated to be upregulated in FLSs after stimulation with proinflammatory cytokines, such as TNF- $\alpha$ and IL-1 $\beta$ (40). LSD1 has been reported to act as a negative regulator of the Notch signaling pathway through its interaction with the deacetylase SIRT1 in cell cultures (24). The knockdown of LSD1 expression in $\mathrm{CD}^{+}{ }^{+} \mathrm{T}$ cells obtained from active RA synovial fluids has been demonstrated to inhibit cell proliferation and proinflammatory cytokine secretion (20). Consistent with the results in a previous study, the expression of LSD1 was downregulated by the knockdown of CoREST in the present study, and then the proliferation of FLSs was inhibited, in which the Notch signaling pathway may play a regulatory role in RA-FLSs. However, further study is necessary to elucidate the detailed molecular mechanisms through which CoREST participates in RA progression.

The present study had a number of limitations. Primary cells derived from synovial tissues of knee joints were used, and in order to prevent phenotypic drift, cells at a low passage were cultured in medium without growth factors. However, the gene expression profile of synovial cells may have been altered due to adaptation of the cells in the culture conditions. Furthermore, this study was performed by using RA synovial tissues and a TNF- $\alpha$-induced cell model, and an experimental design that more accurately mimics RA-FLFs should be considered in future studies.

The present study revealed that CoREST expression was upregulated in RA-FLSs. TNF- $\alpha$ stimulation increased CoREST expression, which could also increase the proliferation, migration of FLSs through cooperating with LSD1. However, in vivo experiments are required to further verify the function of CoREST in RA and explore its potential applications in clinical practice.

\section{Acknowledgements}

Not applicable.

\section{Funding}

The present study was supported by grants from the Jiangsu Six-One Project (grant no. LGY2020047), the Science \&
Technology Bureau of Nantong (grant no. MA2019005), the Health Commission of Nantong (grant no. JC2019075) and the Health Commission of Nantong (grant no. MB2020005).

\section{Availability of data and materials}

The datasets used and/or analyzed during the current study are available from the corresponding author on reasonable request.

\section{Authors' contributions}

WL, ZY and FC contributed to the design of the work. ZY, FC, HL, JF, XD, XZhu, SC, HY, XZhou and YH carried out the specific experiments. ZY, FC, HL and JF contributed to the acquisition and analysis of data, and WL gave the final approval of the version to be published. ZY and FC confirm the authenticity of all the raw data. All authors have read and approved the final manuscript, and guaranteed the integrity of the work.

\section{Ethics approval and consent to participate}

The procedures and processes of the present study were reviewed and approved by the institutional medical ethics committee of The Second Affiliated Hospital of Nantong University (Nantong, China). Patients provided written informed consent to participate before they received any treatment.

\section{Patient consent for publication}

Not applicable.

\section{Competing interests}

The authors declare that they have no competing interests.

\section{References}

1. McInnes IB and Schett G: Pathogenetic insights from the treatment of rheumatoid arthritis. Lancet 389: 2328-2337, 2017.

2. Rossini M, Caimmi C, Bernardi D, Rossi E, Viapiana O, Rosa MD and Adami S: Epidemiology and hospitalization rate of rheumatoid arthritis patients in real world setting in Italy. Ann Rheumatic Diseases 72 (Suppl 3): A409-A409, 2013.

3. Rossini M, Rossi E, Bernardi D, Viapiana O, Gatti D, Idolazzi L, Caimmi C, Derosa M and Adami S: Prevalence and incidence of rheumatoid arthritis in Italy. Rheumatol Int 34: 659-664, 2014.

4. Sung YK, Cho SK, Choi CB and Bae SC: Prevalence and incidence of rheumatoid arthritis in South Korea. Rheumatol Int 33: 1525-1532, 2013.

5. Klareskog L, Gregersen PK and Huizinga TW: Prevention of autoimmune rheumatic disease: State of the art and future perspectives. Ann Rheum Dis 69: 2062-2066, 2010.

6. Essouma M and Noubiap JJ: Is air pollution a risk factor for rheumatoid arthritis? J Inflamm (Lond) 12: 48, 2015.

7. Hu Y, Costenbader KH, Gao X, Al-Daabil M, Sparks JA Solomon DH, Hu FB, Karlson EW and Lu B: Sugar-sweetened soda consumption and risk of developing rheumatoid arthritis in women. Am J Clin Nutr 100: 959-967, 2014.

8. van der Linden MP, le Cessie S, Raza K, van der Woude D, Knevel R, Huizinga TW and van der Helm-van Mil AH: Long-term impact of delay in assessment of patients with early arthritis. Arthritis Rheum 62: 3537-3546, 2010.

9. Bartok B and Firestein GS: Fibroblast-like synoviocytes: Key effector cells in rheumatoid arthritis. Immunol Rev 233: 233-255, 2010. 
10. Pap T, Meinecke I, Müller-Ladner U and Gay S: Are fibroblasts involved in joint destruction? Ann Rheum Dis 64 (Suppl 4): iv52-iv54, 2005.

11. Müller-Ladner U, Pap T, Gay RE, Neidhart M and Gay S: Mechanisms of disease: The molecular and cellular basis of joint destruction in rheumatoid arthritis. Nat Clin Pract Rheumatol 1: 102-110, 2005.

12. Huber LC, Distler O, Tarner I, Gay RE, Gay S and Pap T: Synovial fibroblasts: Key players in rheumatoid arthritis. Rheumatology (Oxford) 45: 669-675, 2006.

13. Guo X, Zhang D, Zhang X, Jiang J, Xue P, Wu C, Zhang J, Jin G, Huang Z, Yang J, et al: Dyrk1A promotes the proliferation, migration and invasion of fibroblast-like synoviocytes in rheumatoid arthritis via down-regulating Spry2 and activating the ERK MAPK pathway. Tissue Cell 55: 63-70, 2018.

14. Malemud CJ: Matrix metalloproteinases (MMPs) in health and disease: An overview. Front Biosci 11: 1696-1701, 2006.

15. Mor A, Abramson SB and Pillinger MH: The fibroblast-like synovial cell in rheumatoid arthritis: A key player in inflammation and joint destruction. Clin Immunol 115: 118-128, 2005.

16. Liu J, Fei D, Xing J and Du J: MicroRNA-29a inhibits proliferation and induces apoptosis in rheumatoid arthritis fibroblast-like synoviocytes by repressing STAT3. Biomed Pharmacother 96: 173-181, 2017.

17. Coulson JM: Transcriptional regulation: Cancer, neurons and the REST. Curr Biol 15: R665-R668, 2005.

18. Majumder S: REST in good times and bad: Roles in tumor suppressor and oncogenic activities. Cell Cycle 5: 1929-1935, 2006.

19. Andrés ME, Burger C, Peral-Rubio MJ, Battaglioli E, Anderson ME, Grimes J, Dallman J, Ballas N and Mandel G: CoREST: A functional corepressor required for regulation of neural-specific gene expression. Proc Natl Acad Sci USA 96: 9873-9878, 1999.

20. Liu W, Fan JB, Xu DW, Zhu XH, Yi H, Cui SY, Zhang J and Cui ZM: Knockdown of LSD1 ameliorates the severity of rheumatoid arthritis and decreases the function of CD4 T cells in mouse models. Int J Clin Exp Pathol 11: 333-341, 2018.

21. Ceballos-Chávez M, Rivero S, García-Gutiérrez P, Rodríguez-Paredes M, García-Domínguez M, Bhattacharya S and Reyes JC: Control of neuronal differentiation by sumoylation of BRAF35, a subunit of the LSD1-CoREST histone demethylase complex. Proc Natl Acad Sci USA 109: 8085-8090, 2012.

22. Maiques-Diaz A and Somervaille TC: LSD1: Biologic roles and therapeutic targeting. Epigenomics 8: 1103-1116, 2016.

23. Shi YJ, Matson C, Lan F, Iwase S, Baba T and Shi Y: Regulation of LSD1 histone demethylase activity by its associated factors. Mol Cell 19: 857-864, 2005.

24. Mulligan P, Yang F, Di Stefano L, Ji JY, Ouyang J, Nishikawa JL, Toiber D, Kulkarni M, Wang Q, Najafi-Shoushtari SH, et al: A SIRT1-LSD1 corepressor complex regulates notch target gene expression and development. Mol Cell 42: 689-699, 2011.

25. Wang SC: PCNA: A silent housekeeper or a potential therapeutic target? Trends Pharmacol Sci 35: 178-186, 2014.

26. Aaltomaa S, Lipponen P and Syrjänen K: Proliferating cell nuclear antigen (PCNA) immunolabeling as a prognostic factor in axillary lymph node negative breast cancer. Anticancer Res 13: 533-538, 1993.
27. Aletaha D, Neogi T, Silman AJ, Funovits J, Felson DT, Bingham CO III, Birnbaum NS, Burmester GR, Bykerk VP, Cohen MD, et al: 2010 rheumatoid arthritis classification criteria: An American college of rheumatology/European league against rheumatism collaborative initiative. Arthritis Rheum 62 2569-2581, 2010

28. Livak KJ and Schmittgen TD: Analysis of relative gene expression data using real-time quantitative PCR and the 2(-Delta Delta C(T)) method. Methods 25: 402-408, 2001.

29. Alsaleh G, François A, Knapp AM, Schickel JN, Sibilia J, Pasquali JL, Gottenberg JE, Wachsmann D and Soulas-Sprauel P: Synovial fibroblasts promote immunoglobulin class switching by a mechanism involving BAFF. Eur J Immunol 41: 2113-2122, 2011.

30. Chen Z, Lin CX, Song B, Li CC, Qiu JX, Li SX, Lin SP, Luo WQ, $\mathrm{Fu}$ Y, Fang GB, et al: Spermidine activates RIP1 deubiquitination to inhibit TNF- $\alpha$-induced NF- $\kappa \mathrm{B} / \mathrm{p} 65$ signaling pathway in osteoarthritis. Cell Death Dis 11: 503, 2020.

31. Peng M, Qiang L, Xu Y, Li C, Li T and Wang J: IL-35 ameliorates collagen-induced arthritis by promoting TNF- $\alpha$-induced apoptosis of synovial fibroblasts and stimulating M2 macrophages polarization. FEBS J 286: 1972-1985, 2019.

32. Zhang X, Zhang D, Wang Q, Guo X, Chen J, Jiang J, Li M, Liu W, Gao Y, Zhang Q, et al: Sprouty2 inhibits migration and invasion of fibroblast-like synoviocytes in rheumatoid arthritis by down-regulating ATF2 expression and phosphorylation. Inflammation 44: 91-103, 2021

33. Rooprai HK and McCormick D: Proteases and their inhibitors in human brain tumours: A review. Anticancer Res 17: 4151-4162, 1997.

34. Zhang G, Liao Y, Yang H, Tao J, Ma L and Zuo X: Irigenin reduces the expression of caspase- 3 and matrix metalloproteinases, thus suppressing apoptosis and extracellular matrix degradation in TNF- $\alpha$-stimulated nucleus pulposus cells. Chem Biol Interact 349: 109681, 2021.

35. Taghadosi M, Adib M, Jamshidi A, Mahmoudi M and Farhadi E: The 553 status in rheumatoid arthritis with focus on fibroblast-like synoviocytes. Immunol Res 69: 225-238, 2021.

36. Mousavi MJ, Karami J, Aslani S, Tahmasebi MN, Vaziri AS, Jamshidi A, Farhadi E and Mahmoud M: Transformation of fibroblast-like synoviocytes in rheumatoid arthritis; from a friend to foe. Auto Immun Highlights 12: 3, 2021.

37. Zhang Y, Wu T, Wang Y, Zhao X, Zhao B, Zhao X, Zhang Q, Jin Y, Li Z and $\mathrm{Hu} \mathrm{X}$ : The R251Q mutation of LSD1 promotes invasion and migration of luminal breast cancer cells. Int J Biol Macromol 164: 4000-4009, 2020.

38. Lan F, Nottke AC and Shi Y: Mechanisms involved in the regulation of histone lysine demethylases. Curr Opin Cell Biol 20: 316-325, 2008

39. Brennan FM, Maini RN and Feldmann M: TNFo-A pivotal role in rheumatoid arthritis? Rheumatology 31: 293-298, 1992

40. Muller-Ladner U, Gay RE and Gay S: Activation of synoviocytes. Curr Opin Rheumatol 12: 186-194, 2000.

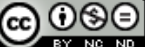

This work is licensed under a Creative Commons Attribution-NonCommercial-NoDerivatives 4.0 International (CC BY-NC-ND 4.0) License. 